\title{
Developing A Knowledge Base on Climate Change For Metropolitan cities
}

Eric Thivant, Eunika Mercier-Laurent, Guilaine Talens Centre de Recherche Magellan, Université Jean Moulin Lyon 3

\section{Abstract}

Studying climate change requires taking into consideration multiple factors that influence it. Finding and understanding the degree of importance of these factors as well as their interinfluences could provide indicators on how to apply these principles among others in growing metropolitan cities. Public, semi-public \& private actors (research laboratories, government agencies, etc.), associations, NGOs, mobilize and participate in new discoveries in related fields and experiment; some of them involve citizens (Smart Cities, Enoll, Triple Helix, etc.).

French Metropolitan Cities have developed their PCETs program (Territorial Climate and Energy Plan) to meet the objectives set by the European Union for 2020 and the National Climate Plan, set out in the Grenelle I and Grenelle II laws in France. In 2007, as part of its Climate Energy Plan, the Lyon metropolitan area made a commitment to reduce $\mathrm{CO} 2$ emissions by $20 \%$ by 2020 ( $75 \%$ by 2050 ), to cut energy consumption by $20 \%$ and to consume $20 \%$ of renewable energies.

This article propose defining and initiate a knowledge base on climate change starting from WEEE (waste electrical and electronic equipment) in large Metropolitan cities such as Metropole of Lyon and Metropole of Montpellier. This Knowledge base will contain best (and bad) practices, experiences, suited metrics, collaborative measures, projects, etc., using the Knowledge Management approach exploring artificial intelligence techniques. For our methodology we work on the state of the art for building such a knowledge base, taking into account the works of D. Boulanger (2005), E. Mercier-Laurent $(2015,2018)$ or G. Kayakutlu \& E. Mercier-Laurent (2016) on that particular field, and we begin to list existing materials in order to implement in a near future a little knowledge base, on the recycling of products, particularly electronic products for these metropolitan cities.

Keywords 
1. Introduction

Studying climate change requires to take into consideration multiple factors that influence it. Finding and understanding the degree of importance of these factors as well as their interinfluences could provide indicators on how to apply these principles in growing metropolitan cities. Public, semi-public \& private actors (research laboratories, government agencies, etc.), associations, NGOs, mobilize and participate in new discoveries in related fields and experiment; some of them involve citizens (Smart Cities, Enoll, Triple Helix, etc.).

The Metropolis of Lyon case Study:

French Metropolitan Cities have developed their PCETs program (Territorial Climate and Energy Plan) to meet the objectives set by the European Union for 2020 and the National Climate Plan, set out in the Grenelle I and Grenelle II laws in France. In 2007, as part of its Climate Energy Plan, the Metropolis of Lyon made a commitment to reduce $\mathrm{CO} 2$ emissions by $20 \%$ by 2020 ( $75 \%$ by 2050), to cut energy consumption by $20 \%$ and to consume $20 \%$ of renewable energies.

The Metropolis of Lyon has launched a "territorial climate-energy plan" (PCET), i.e. a territorial sustainable development project, whose primary purpose is to combat climate change in 2007. The first plan was designed for the period 2010-2020. Then Lyon Metropole has voted a new plan in December 2019, called "Plan climate air energy territorial" (PCAET) for the period 20202030.

"The metropolis of Lyon is working with its 145 partners to take effective action throughout its territory: the Climate and Territorial Energy Plan, which brings together local authorities, industrial and energy producers, companies in the tertiary sector, research laboratories and associations. »

\begin{tabular}{|c|c|c|c|c|c|}
\hline & Transports de passagors & $\begin{array}{l}\text { Traneperts de } \\
\text { marchandises }\end{array}$ & Habitht & Tertiaire & Instries \\
\hline Tendanciel & $\begin{array}{l}\text { Evolution démographique : } \\
+12,3 \%\end{array}$ & $\begin{array}{l}\text { Evolution des } \\
\text { performances } \\
\text { des moteurs: } \\
-15 \%\end{array}$ & $\begin{array}{l}\text { Rénovation tendancielle } \\
\text { des logements : }-6 \%\end{array}$ & $\begin{array}{l}\text { Augmentation de las } \\
\text { population, du taux d'emplai } \\
\text { et de la part du tertiaire } \\
\text { dans l'emplai : }+16 \%\end{array}$ & $\begin{array}{l}\text { Efficacité énergétique, } \\
\text { substitution beis et crise } \\
\text { économique : }-15 \%\end{array}$ \\
\hline $\begin{array}{l}\text { Actions du Plan } \\
\text { Climat Energie }\end{array}$ & $\begin{array}{l}\text { Trensports en commun : } \\
-10 \% \text { (ACTION 4.3) } \\
\text { Modes doux : - } 9 \% \\
\text { (ACTION 2.1) } \\
\text { Covoiturage : }-4,5 \% \\
\text { (ACTION 3.2) } \\
\text { Densification et limitation de } \\
\text { Pusege de la voiture: - } 10 \% \\
\text { (ACTION 2.4) }\end{array}$ & $\begin{array}{l}\text { Optimisation de } \\
\text { la logistique: } \\
-5 \% \\
\text { (ACTION 2.7) }\end{array}$ & $\begin{array}{l}\text { Sabrieté: : }-7 \% \\
\text { (ACTION 2.3) } \\
\text { Rénavation BBC du parc } \\
\text { existant: - } 14 \% \\
\text { (ACTION 4.4 et 4.5) } \\
\text { Constructions neuves } \\
\text { performantes : }-1 \% \\
\text { (ACTION 4.2) } \\
\text { Fort raccordement au } \\
\text { réseau de chaleur: }-1 \% \\
\text { (ACTION 2.2) }\end{array}$ & $\begin{array}{l}\text { Densification : }-2 \% \\
\text { (ACTION 2.3) } \\
\text { Efficacitie des Equipements: } \\
-2 \% \text { (ACTION 4.7) } \\
\text { Sobriëté : }-7 \% \text { (ACTION } 3.3 \text { ) } \\
\text { Rénovation BBC: }-11 \% \\
\text { (ACTION 6.1) } \\
\text { Constructions neuves } \\
\text { performantes : }-5 \% \\
\text { (ACTION 4.2) }\end{array}$ & $\begin{array}{l}\text { Poursuite des actions } \\
\text { defficasité énergeitque : } \\
-3,2 \% \text { (ACTION 2.2) } \\
\text { Substitution bois sur } \\
\text { les réseasx de chaleur } \\
\text { urbains : }-2,4 \% \\
\text { (ACTION } 49 \text { ) }\end{array}$ \\
\hline Objectff en 2020 & $-21 \%$ & $-20 \%$ & $-28 \%$ & $-11 \%$ & $-20,6 \%$ \\
\hline
\end{tabular}

The Lyon Metropole has 3 objectives to achieve:

- $17 \%$ renewable energy in 2030

- 43\% CO2 emissions compared to 2000

- $30 \%$ \&energy consumption compared to 2000 
This article propose defining and initiate an knowledge base on climate change and more specifically on the WEEE (waste electrical and electronic equipment). We focus on large Metropolitan cities such as Metropole of Lyon or Metropole of Montpellier in order to develop such a Knowledge base. It will contain best (and bad) practices, experiences, suited metrics, collaborative measures, projects, etc., using the Knowledge Management approach based on artificial intelligence techniques.

\section{State of Art or related works on KM \& Ontology}

Concerning our state of art, we first define what is an ontology and then we concentrate on the SCO (Smart City Ontology).. Since 90s some researchers in "ingénierie des connaissances" field want to develop new SCB system and propose to use ontology to resolve SCB problems.

[GRUB 93:199] explains to us that "A body of formally represented knowledge is based on a conceptualization: the objects, concepts and other entities that are presumed to exist in some area of interest and the relationships that hold among them (Genesereth \& Nilsson, 1987). A conceptualization is an abstract, simplified view of the world that we wish to represent for some purpose. Every knowledge base, knowledge-based system or knowledge-level agent is committed to some conceptualization, explicity or implicitly".

[GRUB 93:199] continue his thinking and define the concept of ontology : "An ontology is an explicit specification of a conceptualization. The term is borrowed from philosophy, where an ontology is a systematic account of Existence. For Knowledge-based systems, what exists is exactly that which can be represented. When the knowledge of a domain is represented in a declarative formalism, the set of objects, that can be represented is called the universe of discourse. This set of objects and the formalized relationships among them, are reflected in the representational vocabulary with which a knowledge-based program represents knowledge. Thus we can describe the ontology of a program by defining a set of representational terms."

Inside the ontology, "definitions associate the names of entities in the universe of discourse (e.g. classes, relations, functions, or other objects) with human readable text describing what the names are meant to denote, and formal axioms that constrain the interpretation and wellformed use of these terms."

The definition of Studer [13] based on Gruber [14] is:" An ontology is a formal, explicit specification of a shared conceptualization". 'Formal' refers to the fact that the ontology should be machine understandable, excludes natural language. 'Shared' reflects the notion, an ontology captures consensual knowledge, that is, it is not private to some individual, but accepted by a group". 


\section{Methodology}

For our methodology we work on the state of the art for building such a knowledge base, taking into account the works of D. Boulanger (2005), E. Mercier-Laurent $(2015,2018)$ or DG. Kayakutlu \& E. Mercier-Laurent (2016) on that particular field, and we begin to list existing materials in order to implement in a near future a little knowledge base, on the recycling of products, particularly electronic products for these metropolitan cities.

For example, [MER 11] has developed the concept of ontology of innovation... innovation has

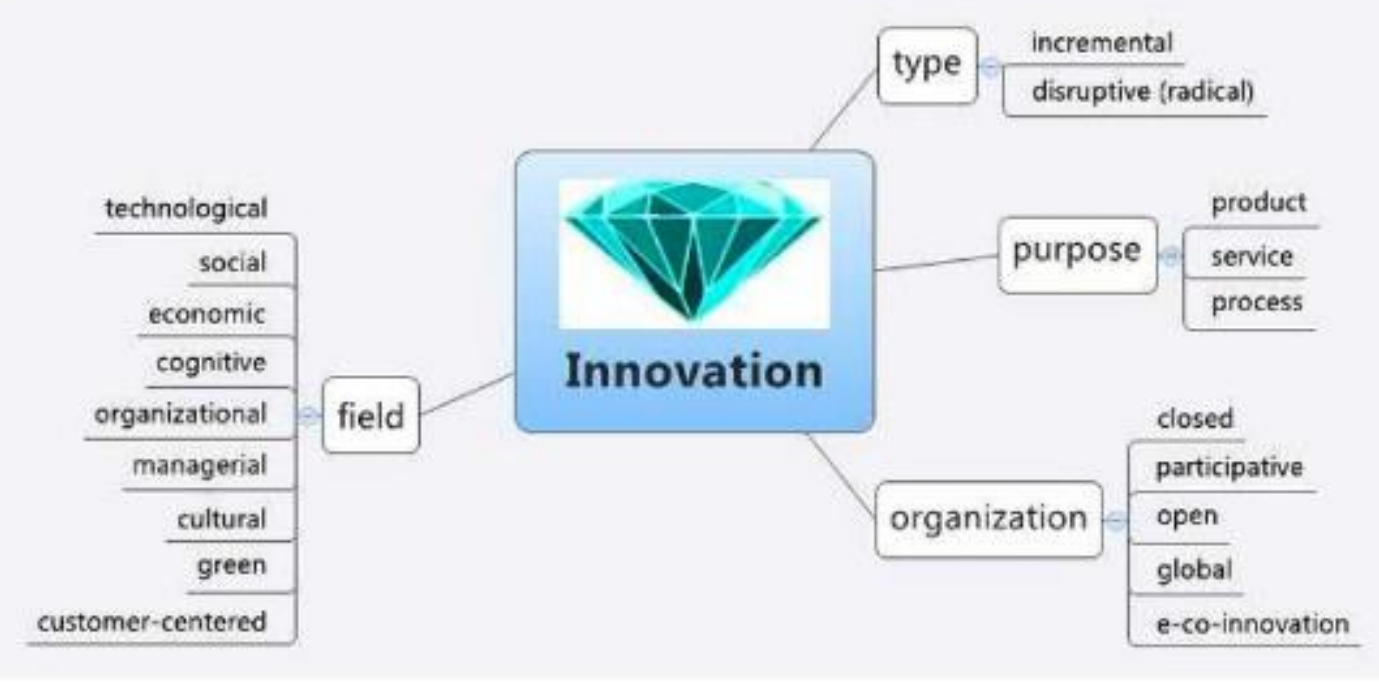

Figure 1: Ontology of Innovation [MER 11]

In order to build our ontology, we can use the following set of 5 criteria proposed by Gruber [15] : Clarity, Coherence, Extendibility, minimal encoding bias, Minimal ontological commitment. Clarity means that ". Coherence means "An ontology should effectively communicate the intended meaning of defined terms. Definitions should be objective."; For Coherence: "An ontology should be coherent: that is, it should sanction inferences that are consistent with the definitions. At the least, the defining axioms should be logically consistent".; Extendibility: "An ontology should be designed to anticipate the uses of the shared vocabulary. It should offer a conceptual foundation for a range of anticipated tasks, and the representation should be crafted so that one can extend and specialize the ontology monotonically". Minimal encoging bias "The conceptualization should be specified at the knowledge level without depending on a particular symbol-level encoding. An encoding bias results when a representation choice are made purely for the convenience of notation or implementation."; Minimal ontological commitment: "An ontology should require the minimal ontological commitment sufficient to support the intended knowledge sharing activities. An ontology should make as few claims as possible about the world being modeled, allowing the parties committed to the ontology freedom to specialize and instantiate the ontology as needed". 


\section{Presentation of the SCO (smart city Ontology)}

Nicos Komninos ${ }^{*}$, Charalampos Bratsas, Christina Kakderi and Panagiotis Tsarchopoulos (2015) have developed a Smart City Ontology. This Ontology is specifically built for Smart Cities, because there are a lot of ontologies existing already and they want to propose a new on more clear... The authors have reviewed the existing ontologies for cities such as SOFIA, NOW, SCRIBE, etc. and then they define the buildings blocks of this ontology with respect to the most cited definitions of smart cities and structuring this ontology with the Protégé 5.0 editor, defining entities, class hierarchy and object properties and data type properties. review also the building blocks of smart or intelligent cities, which allows to define the class and properties of the SCO.

According to the authors: "The first version (v01) contains 10 superclasses, 708 entities, 422 classes, 62 object properties, 190 data properties, and 27 individ-uals from the software application class. Additionally, widely adopted extra ontologies are used, enriching the SCO, such as the Simple Knowledge Organization System (SKOS), a W3C recommendation designed for representation of thesauri, classification schemes, taxonomies, subject-heading systems, or any other type of structured controlled vocabulary[21]." You can see below in the graph the structure of the first level of the ontology.

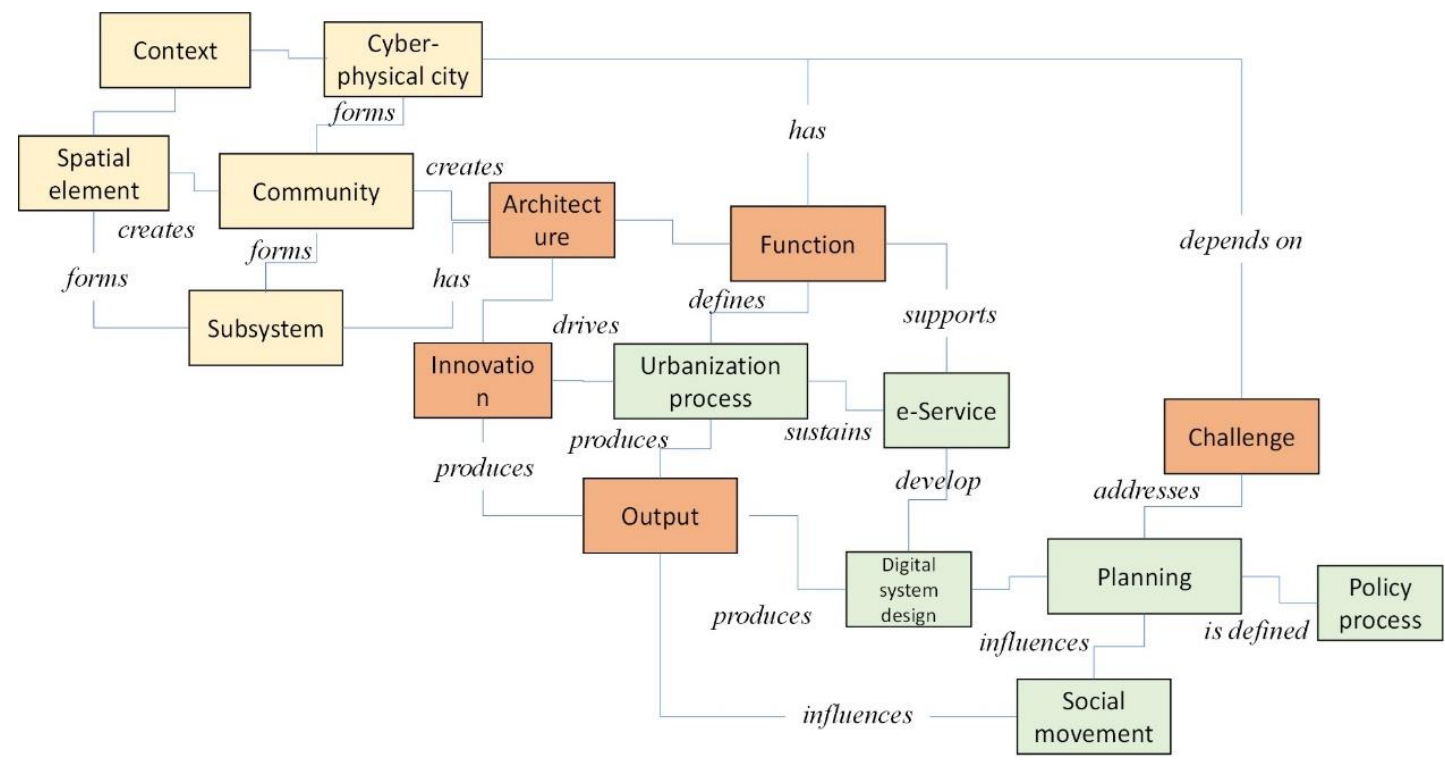

Figure 2: An new view of the Smart City Ontology of Professor Nicos Komninos \& al. (2020)

In [GYRAR 2018], smart city ontologies are presented and compared in order to be applied to IoT ontologies. The set of criteria are mainly focused on the reusability of the ontologies. The goal is to define a methodology to enrich smart city catalogs with the new ontologies found. It's implemented within the LOV4loT ontology catalog. The aim of this catalog is to help developers in reusing existing smart city and loT ontologies to build future applications.

\section{ONTOLOGIES FOR CLIMATE CHANGE}

[Pilegi and Lamia 2020] build an ontology to describe the climate change story from multiple perspectives, including scientific, social, political and technological ones.

In this article, several ontologies for climate are cited, ontologies to measure the impact of a changing climate on food and waterborne diseases, the impacts of agriculture on water resources, ... but there is none ontology to capture the recycling of products. 


\section{Proposal of adding recycling in the SCO}

\subsection{Eco-design a key element for innovation}

[Evbuomwan et al., 1996] defined the eco-design like "the process of establishing requirements based on human needs, transforming them into performance specification and functions, which are then mapped and converted (subject to constraints) into design solutions (using creativity, scientific principles and technical knowledge) that can be economically manufactured and produced".

[Lindhqvist, 1990] proposes the Extended Producer Responsibility (EPR) concept and change the classical view of PPP (the polluter pay for the pollution, from the consumer to the economic agent who produce the goods). According to the Organisation for Economic Co-operation and Development (OECD), EPR is "an environmental policy approach in which a producer's responsibility for a product is extended to the post-consumer stage of a product's life cycle". (Report of Development of Guidance on Extended Producer Responsibility (EPR), European Commission-DG Environment, 2014).

"The economic reasoning behind the EPR concept is to have producers internalise treatment and disposal cost so that they have an incentive to design products that last longer and are more easily treated after use".

Definitions of the EPR System (Development of Guidance on Extended Producer Responsibility)

EPR system or EPR scheme: Any system set up by one or several producers to implement the EPR principle. It can be an individual system (or individual compliance scheme) when a producer organises its own system, or a collective system (collective compliance scheme) when several producers decide to collaborate and thus transfer their responsibility to a specific organisation (a PRO).

Producer Responsibility Organisation or PRO: Entity set up in collective EPR schemes to implement the EPR principle in the name of all the adhering companies.

Fees: Tariff paid by a producer to have its products dealt with through a PRO.

According to the WEEE Directive (2012/19/EU), there are 7 Categories of EEE :

1. Large household appliances

2. Small household appliances

3. IT and telecommunications equipment

4. Consumer equipment and photovoltaic panels

5. Lighting equipment

6. Electrical and electronic tools (with the exception of large-scale stationary industrial tools)

7. Toys, leisure and sports equipment

For each categories of EEE, we should develop our own view on WEEE. 


\subsection{Ecosystem of the recycling circuit}

Natalia Alonso Movilla presents us the physical and financial flows of the WEEE industry below.

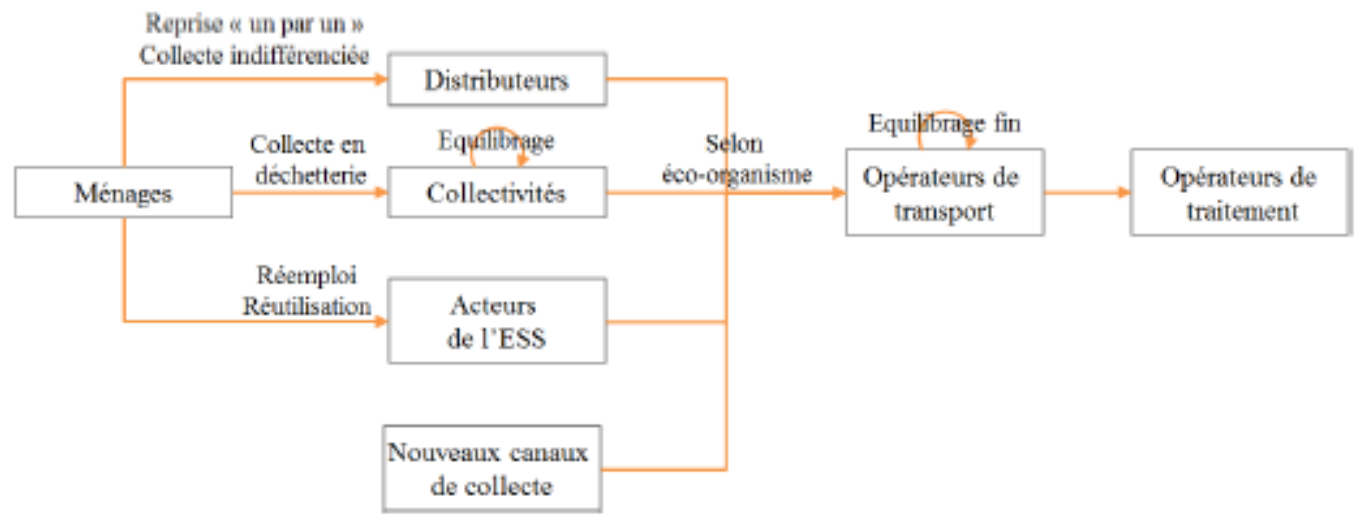

Figure 3: Physical flows of WEEE Industry, from Mérot (2014) and modified by Natalia Alonso Movilla

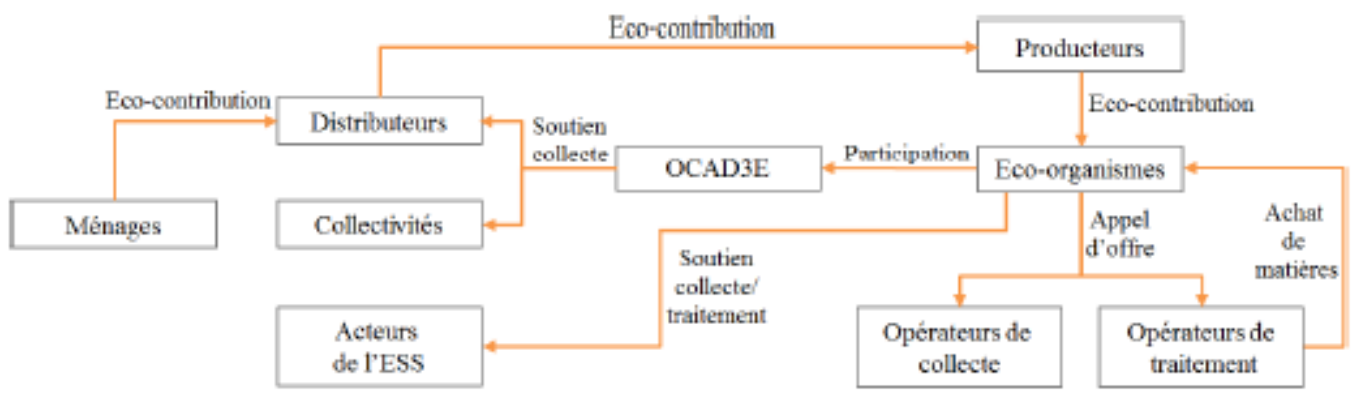

Figure 4: Financial Flows of WEEE Indutry, from Mérot (2014) modified by Natalia Alonso Movilla's thesis

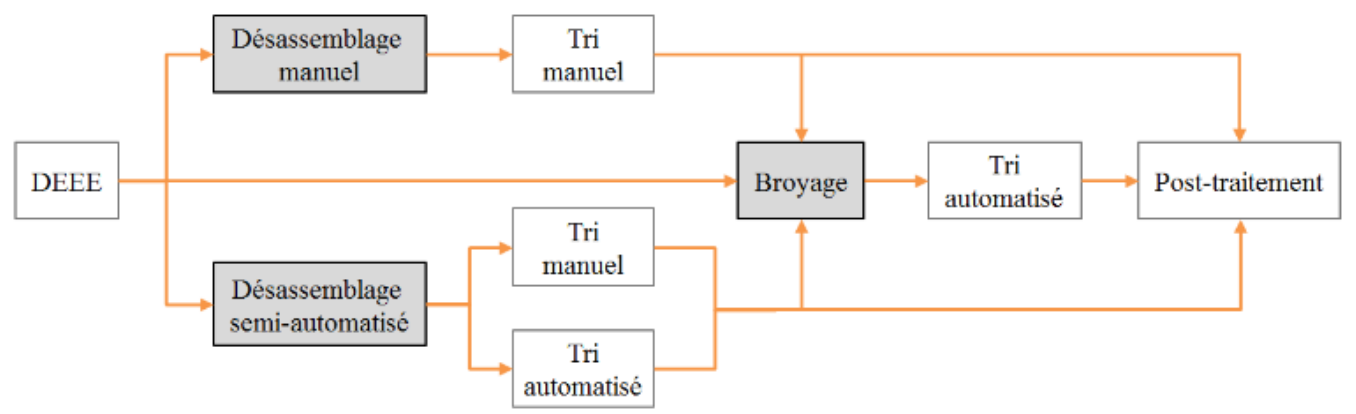

Figure 5: process of dismantling from Natalia Alonso Movilla's thesis 
We propose to add the recycling theme to this SCO ontology, with the following classes \& proprieties from the WEEE domain, It takes different types of organizations, of products and ways of managing Electronics waste.

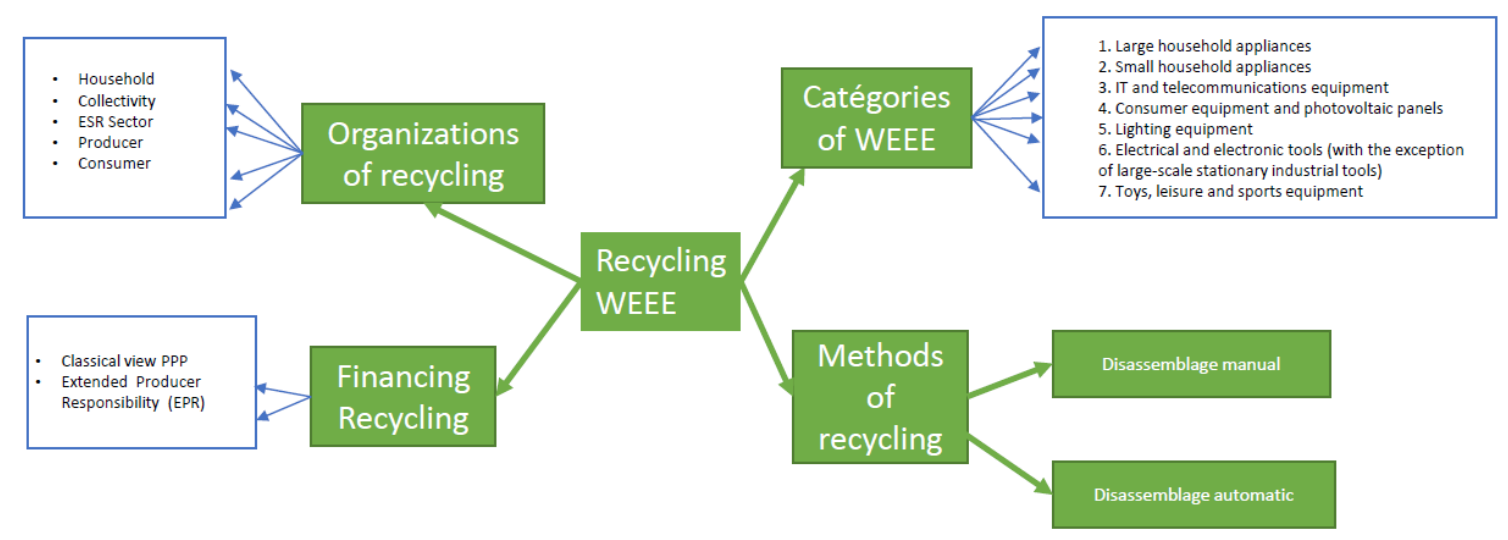

6. Conclusion

Our proposal for a new ontology of this domain, with different classes and proprieties is not yet finish. We need to continue our work with a case-based analysis \& application in order to explain better our classes and the relationships between them. 


\section{$\underline{\text { References }}$}

1. Chamekh F., Boulanger D., Talens G.: Web of Data Evolution by Exploiting Agent BasedArgumentation. In: Mercier-Laurent, E., Boulanger, D. (eds.), AI4KM@IJCAI 2015: 32-50. Springer, Cham (2015).

2. Colloc J., Boulanger D.: Automatic Knowledge Acquisition for Object-Oriented Expert Systems. CoRR abs/2005.08517 (2020).

3. European Union (2013), Green Paper: A 2030 framework for climate and energy policies, available at: https://ec.europa.eu/clima/policies/strategies/2030 en\#tab-0-1 \& https://eurlex.europa.eu/legal-content/EN/TXT/?uri=CELEX:52013DC0169

4. Hauke K., Owoc M. L., Pondel M.: Usability of Knowledge portals for Exclusives in Local Governments, In: Mercier-Laurent, E., Owoc, M. L., Boulanger, D. (eds.), Al4KM@IJCAI 2014: 92-106. Springer, Cham (2014).

5. Kayakutlu, DG., Mercier-Laurent, E.: Intelligence in Energy. Elsevier, London (2016).

6. Mercier-Laurent E.: Platform for Knowledge Society and Innovation Ecosystems. In: MercierLaurent, E., (eds.), AI4KM@IJCAI 2018: 34-47. Springer, Cham (2020).

7. Mercier-Laurent, E.: Managing intellectual capital in knowledge economy. In: Mercier-Laurent, E., Owoc, M., Boulanger, D. (eds.) AI4KM 2014. IAICT, vol. 469, pp. 165-179. Springer, Cham (2015). https://doi.org/10.1007/978-3-319-28868-0_10

8. Mercier-Laurent, E.: The Innovation Biosphere. Wiley, London (2015).

9. Métropole de Lyon, Projet de Plan Climat Air Énergie Territorial, 2018-2019, available at : https://www.grandlyon.com/fileadmin/user upload/media/pdf/grands-projets/concertationreglementaire/20190524 projet-pcaet.pdf

10. Métropole de Lyon, Rapport Environnemental PCAET April 2019, available at : https://www.grandlyon.com/fileadmin/user upload/media/pdf/grands-projets/concertationreglementaire/20190429 rapport-environnemental-pcaet.pdf

11. Przysucha $\measuredangle$.: Effective Management of Information Processes with CMS in Smart City. The Concept of Crowdsourcing. In: Mercier-Laurent, E., (eds.), Al4KM@IJCAI 2018: 65-76. Springer, Cham (2020).

12. Wojtusiak J., Mercier-Laurent E., Punihaole C.: Introduction to the Minitrack on Al and Sustainability: The Use of Al in Sustainability Initiatives. HICSS 2020: 1-2

13. Studer R., Benjamins D., Fensel D., «Knowledge Engineering: Principles and Methods », In IEEE Transactions on Data and Knowledge Engineering, Vol. 25, Issue 1-2, pp. 161-197. (1998),

14. Gruber T.R., «A translation approach to portable ontologies », Knowledge acquisition, Vol. 5, n², , pp. 199-220. (1993).

15. Gruber, T.R. Toward Principles for the Design of Ontologies Used for Knowledge Sharing. International Journal Human-Computer Studies, Vol. 43, Issues 5-6, p.907-928, November (1995),

16. Mérot, A.-S., 2014. Gouvernance et développement durable : le cas de la responsabilité élargie du producteur dans la filière de gestion des déchets des équipements électriques et électroniques. Grenoble.

17. Nicos Komninos, Anastasia Panori, Christina Kakderi, 2020, Smart City Ontology 2.0, available at https://www.urenio.org/2020/12/16/smart-city-ontology-2-0/

18. Komninos N., Bratsas C., Kakderi C., Tsarchopoulos P. 2015, Smart city ontologies: Improving the effectiveness of smart city applications. Journal of Smart Cities, vol.1(1): 31-46. http://dx.doi.org/10.18063/JSC.2015.01.001

19. Gyrard, A., Zimmermann, A., \& Sheth, A. P. (2018). Building loT Based Applications for Smart Cities: How Can Ontology Catalogs Help?. IEEE Internet of Things Journal, 5 (5), 3978-3990. https://corescholar.libraries.wright.edu/knoesis/1147

20. Pileggi S. P., Lamia, A.V. (2020), Climate Change TimeLine: An Ontology to Tell the Story so Far, IEEE access, volume 8, 10.1109/ACCESS.2020.2985112 


\section{Other references}

21. E. Mercier-Laurent, D. Boulanger: Artificial Intelligence for Knowledge Management - 5th IFIP WG 12.6 International Workshop, Al4KM 2017, Held at IJCAI 2017, Melbourne, VIC, Australia, August 20, 2017, Revised Selected Papers. IFIP Advances in Information and Communication Technology 571, Springer 2019, ISBN 978-3-030-29903-3

22. Eunika Mercier-Laurent, Danielle Boulanger:Artificial Intelligence for Knowledge Management - 4th IFIP WG 12.6 International Workshop, AI4KM 2016, Held at IJCAI 2016, New York, NY, USA, July 9, 2016, Revised Selected Papers. IFIP Advances in Information and Communication Technology 518, Springer 2018, ISBN 978-3-319-92927-9

23. Eunika Mercier-Laurent, Mieczyslaw Lech Owoc, Danielle Boulanger: Artificial Intelligence for Knowledge Management - Second IFIP WG 12.6 International Workshop, Al4KM@FedCSIS 2014, Warsaw, Poland, September 7-10, 2014, Revised Selected Papers. IFIP Advances in Information and Communication Technology 469, Springer 2015, ISBN 978-3-319-28867-3

24. Eunika Mercier-Laurent, Danielle Boulanger: Artificial Intelligence for Knowledge Management - Third IFIP WG 12.6 International Workshop, Al4KM 2015, Held at IJCAI 2015, Buenos Aires, Argentina, July 25-31, 2015, Revised Selected Papers. IFIP Advances in Information and Communication Technology 497, 2016, ISBN 978-3-319-55969-8

25. E. Mercier-Laurent, D. Boulanger: Artificial Intelligence for Knowledge Management - First IFIP WG 12.6 International Workshop, Al4KM 2012, Held in Conjunction with ECAI 2012, Montpellier, France, August 28, 2012, Revised Selected Papers. IFIP Advances in Information and Communication Technology 422, Springer 2014, ISBN 978-3-642-54896-3 